\title{
Liquid flow equations for drainage systems composed of two layers including a geocomposite
}

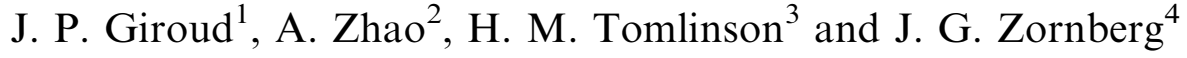 \\ ${ }^{1}$ Chairman Emeritus, GeoSyntec Consultants, JP Giroud, Inc., 5837 North Ocean Blvd, Ocean \\ Ridge, FL 33435, USA, Telephone: + 1561737 1642, Telefax: + 1561733 2809, \\ E-mail: jpg@jpgiroud.com \\ ${ }^{2}$ Vice President of Engineering, Tenax Corp., 4800 E. Monument Street, Baltimore, MD 21205, \\ USA, Telephone: +1410522 7000,Telefax: +1410522 7015,E-mail: azhao@tenax.com \\ ${ }^{3}$ Project Engineer, GeoSyntec Consultants, 621 N.W. 53rd Street, Suite 650, Boca Raton, \\ FL 33487, USA, Telephone: + 1561995 0900, Telefax: + 15619950925 , \\ E-mail: htomlinson@geosyntec.com \\ ${ }^{4}$ Clyde E. Lee Assistant Professor, Department of Civil Engineering, The University of Texas at \\ Austin, 1 University Station C1792, Austin, TX 78712-0280, USA, \\ Telephone: + 1512232 3595, Telefax: + 1512471 6548, E-mail: zornberg@mail.utexas.edu
}

Received 24 June 2001, revised 29 January 2004, accepted 1 February 2004

\begin{abstract}
The focus of this paper is on applications (e.g. some leachate collection layers in landfills) where a drainage system consists of a geocomposite overlain by a sand layer. If the geocomposite does not have sufficient flow capacity to convey all the collected liquid, a fraction of the liquid flows in the sand layer. In such drainage systems, the maximum liquid thickness should be calculated to check that the flow capacity of the sand is not exceeded, and the maximum head should be calculated to check that it is less than the maximum head prescribed by regulations. This paper presents a method for calculating the maximum liquid thickness and the maximum head in drainage systems composed of two layers, with the lower layer being a geocomposite. Equations give the maximum liquid thickness and the maximum head as a function of the rate of liquid supply, the hydraulic conductivities of the two layers, the length of the drainage system, and the slope. Design examples are presented.
\end{abstract}

KEYWORDS: Geosynthetics, Geocomposite, Geonet, Flow, Liquid, Water, Leachate, Two layers, Drainage, Leachate collection, Hydraulic conductivity, Hydraulic transmissivity

REFERENCE: Giroud, J. P., Zhao, A., Tomlinson, H. M. \& Zornberg, J. G. (2004). Liquid flow equations for drainage systems composed of two layers including a geocomposite. Geosynthetics International, 11, No. 1, 43-58

\section{INTRODUCTION}

\subsection{Scope of this paper}

There are many landfills where the liner is overlain by a leachate collection system that consists of a drainage geocomposite overlain by a sand protective layer (Figure 1). It should be noted that only the upper geotextile of the drainage geocomposite is shown in Figure 1. In many cases, there is a geotextile heat-bonded to the lower face of the geosynthetic drainage medium for stability purposes. This geotextile is not shown in Figure 1 because the focus of this paper is on hydraulic performance. Stability considerations are briefly discussed in Section 5.5.

The geocomposite is typically a few millimeters thick, whereas the sand layer is typically between 0.3 and $0.6 \mathrm{~m}$ thick. Engineers designing such systems are often required to demonstrate that the head of leachate is less than a maximum value prescribed by regulations. This is a challenging problem if leachate flows both in the geocomposite and in the sand.

More generally, there are applications, other than leachate collection systems, where a drainage system consists of two layers. In this paper, the term 'drainage system' will be used generically to designate all types of drainage systems, including leachate collection systems.

The design of a drainage system requires the calculation of the maximum liquid thickness and the maximum head, as explained below:

- The maximum liquid thickness must be less than the thickness of the drainage system for the following reasons: (i) to ensure that the drainage system is not full and, therefore, is able to collect liquid over its 


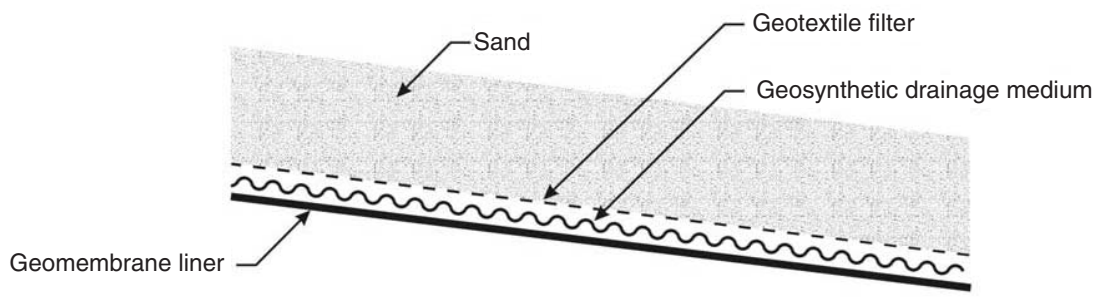

Figure 1. Leachate collection system or other drainage layer composed of a drainage geocomposite overlain by a sand layer

entire area; (ii) to prevent pore pressure build-up in cases where pore pressure can be detrimental to the stability of the drainage system and overlying materials, and in cases where the resulting head may be excessive regarding the risk of leakage through the underlying liner (if any), as explained below; and (iii) in the case of leachate collection layers, to prevent the leachate that is conveyed by the leachate collection layer from being in contact with the waste, which would increase leachate concentration. Also, in the case of drainage systems on steep slopes, the liquid thickness in the drainage system must be as small as possible because the stability of the drainage system and overlying materials is impaired by seepage forces that are proportional to liquid thickness. It should be noted that the term 'thickness' is used instead of the more familiar term 'depth', because thickness (measured perpendicular to the drainage layer slope), and not depth (measured vertically), is actually used in design.

- The maximum head must be as small as possible because the rate of leakage through the liner (if any) underlying the drainage system is a function of the head of liquid above the liner (commonly called 'head'). To that end, regulations applicable to landfill design typically require a demonstration that the head of leachate above the liner is less than a prescribed value, typically $0.3 \mathrm{~m}$. For applications where there is no prescribed value for the maximum head, there may be a project-specific design criterion for the maximum head.

In summary, a drainage system must meet two design criteria: the maximum liquid thickness must be smaller than the thickness of the drainage system, and the maximum head must be smaller than a prescribed value.

As indicated in Section 2.5, the liquid thickness and the head are related: the head is slightly smaller than liquid thickness. In the design of drainage systems that consist of two layers, with a geocomposite as the lower layer, two cases should be considered, depending on the required liquid collection rate and the flow capacity of the drainage geocomposite:

- If the drainage geocomposite has sufficient flow capacity to convey (without being full) all the collected liquid, the liquid thickness in the geocomposite is less than the geocomposite thickness, and the head is very small because the thickness of the geocomposite is small.
- If the drainage geocomposite does not have sufficient flow capacity to convey all the collected liquid, some of the liquid flows in the layer located above the geocomposite (herein referred to as the upper layer). In this case, the designer should check that: (i) the liquid thickness in the upper layer is less than the thickness of the upper layer; and (ii) the total head (i.e. the head in the geocomposite plus the head in the upper layer) is less than the prescribed value.

Based on the foregoing discussion, it is important to have a method for calculating the liquid head and thickness in the case of a drainage system composed of two layers. To the best of the authors' knowledge, no method has been published for this specific case. The purpose of this paper is to provide such a method.

\subsection{Definitions and assumptions}

\subsubsection{The drainage system}

The considered drainage system is located on a slope of angle $\beta$. The drainage system is underlain by a geomembrane liner, which is assumed to be without defects. This assumption is conservative because it means that there is no liquid loss, and therefore the drainage system must be designed to convey all the liquid.

The drainage system is composed of two layers. Each layer is characterised by its thickness and the hydraulic conductivity of the drainage material. The hydraulic conductivity of the lower layer material, $k_{1}$, is assumed to be greater than the hydraulic conductivity of the upper layer material, $k_{2}$ :

$$
k_{1}>k_{2}
$$

where $k_{1}$ is the hydraulic conductivity of the drainage material used in the lower layer, and $k_{2}$ is the hydraulic conductivity of the drainage material used in the upper layer. In this paper, the subscript ' 1 ' will be used for the lower layer and the subscript ' 2 ' for the upper layer. If the drainage materials do not have the same hydraulic conductivities in all directions, $k_{1}$ and $k_{2}$ are assumed to be measured in the direction of the slope.

The hydraulic transmissivity of each layer is the product of the thickness of the layer and the hydraulic conductivity of the material used in the layer. Thus:

$$
\begin{aligned}
& \theta_{1}=k_{1} t_{1} \\
& \theta_{2}=k_{2} t_{2}
\end{aligned}
$$


where $\theta_{1}$ is the hydraulic transmissivity of the lower layer, $t_{1}$ is the thickness of the lower layer, $\theta_{2}$ is the hydraulic transmissivity of the upper layer, and $t_{2}$ is the thickness of the upper layer.

It is assumed that the lower layer consists of a geocomposite. This assumption allows the use of a simple equation to calculate the liquid thickness in the lower layer, which will greatly simplify the analysis. This assumption is discussed in Section 5.6.

An important parameter of the analysis is the length of the drainage layer, $L$. It is important to note that, in accordance with usual practice, $L$ is measured horizontally.

Finally, it is assumed that the two layers of the drainage system are separated and/or protected by properly designed filters. The design of filters is beyond the scope of this paper.

\subsubsection{Liquid supply and flow}

The thickness of liquid in a drainage layer depends on the rate of liquid supply. The rate of liquid supply, $q_{\mathrm{h}}$, is expressed as a volume of liquid per unit of time and per unit area (measured horizontally). The resulting units are expressed in terms of length per time (e.g. $\mathrm{m} / \mathrm{s}, \mathrm{mm} /$ day, in/day). For the analysis presented in this paper, the rate of liquid supply is uniform (i.e. it is the same over the entire area of the drainage layer) and is constant (i.e. it is the same during a period of time that is long enough so that steady-state flow conditions can be reached).

Two examples of drainage systems with a uniform rate of liquid supply can be found in landfills: (i) the drainage system of the landfill cover, where the liquid that impinges onto the drainage system is the precipitation water that has percolated through the soil layer ("cover soil') overlying the drainage system; and (ii) the leachate collection system, where the liquid that impinges onto the leachate collection system is the leachate that has percolated through the waste and through the protective soil layer (if any) overlying the leachate collection system. The terminology 'liquid impingement rate' is often used in the case of landfills to designate the rate of liquid supply.

The rate of liquid supply is assumed to be smaller than the hydraulic conductivity of the upper layer (which is smaller than the hydraulic conductivity of the lower layer, as indicated by Equation 1):

$$
q_{\mathrm{h}}<k_{2}
$$

As a result, the liquid supplied to the drainage system percolates vertically through the drainage system material until it meets the surface of a saturated zone of the drainage system.

The flow rate in a drainage system at a distance $x$ from the top of the slope (Figure 2) is

$$
\frac{Q}{B}=q_{\mathrm{h}} x
$$

where $Q / B$ is the flow rate in the drainage system (in the direction parallel to the slope) per unit length in the horizontal direction perpendicular to the direction of
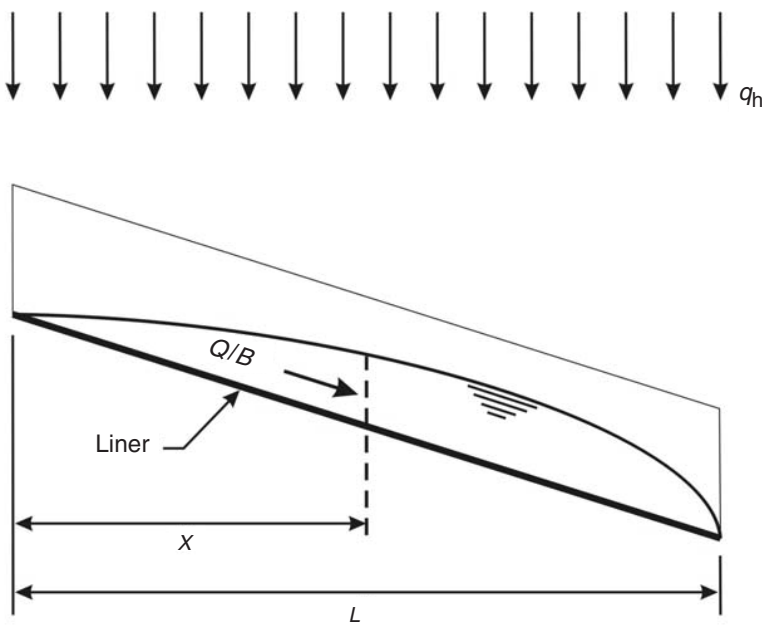

Figure 2. Flow rate per unit width in a drainage layer located on a slope

the flow, $Q$ is the flow rate in the drainage system (in the direction parallel to the slope), $B$ is the unit length in the horizontal direction perpendicular to the direction of the flow, and $x$ is the distance measured horizontally from the top of the slope.

In particular, the flow rate at the toe of the slope is equal to the total amount of liquid supplied per unit of time:

$$
\left(\frac{Q}{B}\right)_{x=L}=q_{\mathrm{h}} L
$$

It is assumed that there is a perfect drain that promptly removes the liquid at the toe of the drainage system. The term 'perfect drain' indicates that the elevation of liquid in the drain located at the toe of the drainage system slope is below the bottom of the drainage system. The liquid thickness is then quasi-zero at the toe of the drainage system, as shown by Giroud et al. (2000). It will be seen that this assumption is not necessary in the limit case described in Section 2.4; this comment is important for the validity of the approach used in this paper.

\subsubsection{Liquid}

The liquid is assumed to be water, or a liquid that has physical characteristics similar to those of water. In particular, the liquid is assumed to be incompressible.

\subsubsection{Reduction factors and factors of safety}

The use of reduction factors (to account for the decrease of hydraulic conductivity and hydraulic transmissivity with time due to clogging and other mechanisms) and factors of safety is not discussed in this paper. Detailed guidance on the use of reduction factors and factors of safety is provided by Giroud et al. (2000).

\subsection{Organization of this paper}

A review of available equations is presented in Section 2; a theoretical analysis is presented in Section 3; numerical applications are presented in Section 4; and a discussion is presented in Section 5. 


\section{REVIEW OF AVAILABLE EQUATIONS}

\subsection{Overview}

Section 2 presents equations that make it possible to calculate the maximum liquid thickness and maximum head in the usual case of a drainage layer subjected to a uniform rate of liquid supply and composed of only one drainage material underlain by an impermeable liner. These equations will be used in the analyses presented in Section 3 to develop equations for drainage systems composed of two layers. These equations are from a detailed study of liquid flow in a drainage layer with a perfect drain at the toe of the slope presented by Giroud et al. (2000).

\subsection{Shape of the liquid surface}

The shape of the liquid surface in a drainage layer subjected to a uniform liquid supply is shown in Figure 3. The shape of the liquid surface depends on the characteristic parameter, $\lambda$, defined as follows (Giroud et al. 2000):

$$
\lambda=\frac{q_{\mathrm{h}}}{k \tan ^{2} \beta}
$$

where $k$ is the hydraulic conductivity of the drainage material in the direction of the flow, and $\beta$ is the slope angle of the drainage layer.

Figure $3 \mathrm{a}$ shows that, when $\lambda$ is greater than 0.25 , the liquid thickness is not zero at the top of the slope. In this case, the liquid surface is horizontal at the top of the slope, which is consistent with a zero hydraulic gradient at the top of the slope, and hence with zero flow through the vertical surface $\mathrm{VV}^{\prime}$ at the top of the slope. The zero flow condition through $\mathrm{VV}^{\prime}$ implies that there is liquid with a zero hydraulic gradient on the other side of $\mathrm{VV}^{\prime}$ (i.e. the left side of $V^{\prime}$ in Figure 3a).

Figure $3 \mathrm{c}$ shows that, when $\lambda$ is very small, the thickness of the liquid in the drainage layer varies linearly from zero at the top to a maximum value near the toe of the drainage layer slope. The maximum liquid thickness occurs exactly at the toe of the slope in the limit case where $\lambda=0$.

\subsection{Maximum liquid thickness}

Regardless of the shape of the liquid surface, the maximum liquid thickness in the drainage layer, $t_{\max }$, is given by the following equation, known as the modified Giroud's equation (Giroud and Houlihan 1995; Giroud et al. 2000):

$$
\begin{aligned}
t_{\max } & =j \frac{\sqrt{\tan ^{2} \beta+4 q_{\mathrm{h}} / k}-\tan \beta}{2 \cos \beta} L \\
& =j \frac{\sqrt{1+4 \lambda}-1}{2} \frac{\tan \beta}{\cos \beta} L
\end{aligned}
$$

where $L$ is the horizontal projection of the length of the drainage layer in the direction of the flow (Figure 2), and (a)

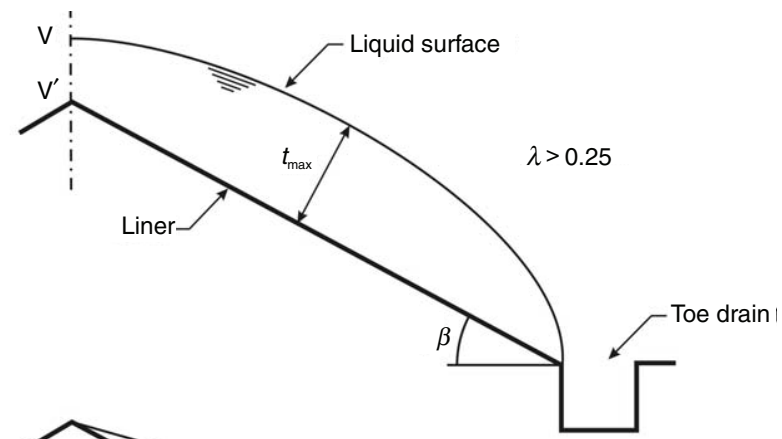

(b)

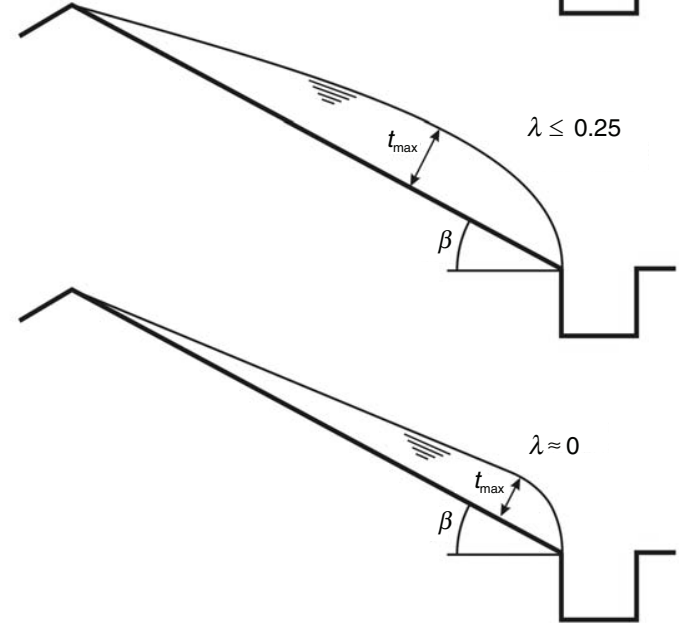

Figure 3. Shape of the liquid surface in a drainage layer as a function of the dimensionless parameter, $\lambda:$ (a) $\lambda>0.25$; (b) $\lambda \leq 0.25$; (c) $\lambda$ very small (reproduced from Giroud et al. 2000) Note: The characteristic parameter $\lambda$ is defined by Equation 7. At the toe of the drainage layer slope, the liquid thickness is very small. At the scale of the figure, it appears to be zero. A very small liquid thickness is possible at the toe of the slope because the liquid surface is vertical at the toe of the slope and, as a result, the hydraulic gradient is very high. In the case where $\lambda \approx 0$, the maximum liquid thickness is approximately equal to $t_{\lim }$ and occurs near the toe of the drainage layer slope.

$j$ is a dimensionless parameter called the 'modifying factor' and defined as follows:

$$
j=1-0.12 \exp \left\{-\left[\log (8 \lambda / 5)^{5 / 8}\right]^{2}\right\}
$$

Numerical values of the modifying factor, $j$, range between 0.88 and 1.00 , as shown in Table 1. Therefore a conservative approximation of Equation 8 is the following equation, which is known as the original Giroud's equation:

$$
\begin{aligned}
t_{\max } & =\frac{\sqrt{\tan ^{2} \beta+4 q_{\mathrm{h}} / k}-\tan \beta}{2 \cos \beta} L \\
& =\frac{\sqrt{1+4 \lambda}-1}{2} \frac{\tan \beta}{\cos \beta} L
\end{aligned}
$$

\subsection{Limit case}

When $\lambda$ is very small (e.g. $\lambda<0.01$ ), which occurs in many practical situations, Equations 8 and 10 are 
Table 1. Numerical values of $j$ as a function of $\lambda$

\begin{tabular}{|ll|cc|rc|}
\hline \multicolumn{1}{|c|}{$\lambda$} & $j$ & $\lambda$ & $j$ & $\lambda$ & $j$ \\
\hline 0 & 1.000 & 0.04 & 0.931 & 5 & 0.913 \\
0.0001 & 1.000 & 0.05 & 0.925 & 6 & 0.918 \\
0.001 & 0.994 & 0.06 & 0.920 & 7 & 0.922 \\
0.002 & 0.989 & 0.07 & 0.916 & 8 & 0.926 \\
0.003 & 0.985 & 0.08 & 0.912 & 9 & 0.929 \\
0.004 & 0.982 & 0.09 & 0.909 & 10 & 0.932 \\
0.005 & 0.978 & 0.10 & 0.906 & 15 & 0.943 \\
0.006 & 0.976 & 0.15 & 0.897 & 20 & 0.950 \\
0.007 & 0.973 & 0.20 & 0.891 & 30 & 0.960 \\
0.008 & 0.970 & 0.25 & 0.887 & 50 & 0.971 \\
0.009 & 0.968 & 0.50 & 0.880 & 100 & 0.982 \\
0.01 & 0.966 & 1 & 0.882 & 200 & 0.990 \\
0.015 & 0.957 & 2 & 0.891 & 500 & 0.996 \\
0.02 & 0.950 & 3 & 0.900 & 1000 & 0.998 \\
0.03 & 0.939 & 4 & 0.907 & 5000 & 1.000 \\
\hline
\end{tabular}

Note: The dimensionless parameter $j$ was calculated using Equation 9. The dimensionless parameter $\lambda$ is defined by Equation 7.

equivalent to the following equation, called the 'limit case equation' (Giroud et al. 2000):

$$
t_{\max } \approx t_{\mathrm{lim}}=\frac{q_{\mathrm{h}}}{k \sin \beta} L=\frac{q_{\mathrm{h}}}{k \tan ^{2} \beta} \frac{\tan \beta}{\cos \beta} L=\lambda \frac{\tan \beta}{\cos \beta} L
$$

where $t_{\lim }$ is the maximum liquid thickness in the limit case where $\lambda$ approaches zero.

As indicated in Figure $3 c$, when $\lambda$ is very small, the thickness of the liquid in the drainage layer varies linearly from zero at the top to a maximum value near the toe of the drainage layer slope. Therefore the following relationship exists when $\lambda$ is very small:

$$
t=\frac{q_{\mathrm{h}}}{k \sin \beta} x=\lambda \frac{\tan \beta}{\cos \beta} x
$$

where $t$ is the liquid thickness at the distance $x$ measured horizontally from the top of the drainage layer in the limit case where $\lambda$ is very small.

It is important to note that the liquid thickness at distance $x$ from the top of the slope is the same whether the total length of the drainage layer is $x$ or greater. This means that it is not necessary to have a perfect drain at the toe of the slope in the limit case where $\lambda$ is very small. The only requirement is that the portion of the drainage layer downstream of abscissa $x$ be able to convey the flow rate that exists at abscissa $x$. This is important for the validity of the approach used in this paper.

Equation 11 is simpler than Equation 10, which in turn is simpler than Equation 8. A detailed discussion of the approximation made when Equation 11 is used is presented by Giroud et al. (2000). The conclusion of the discussion is that: (i) regardless of the value of $\lambda$, Equation 11 provides a conservative value of the maximum liquid thickness (i.e. a value of the maximum liquid thickness greater than the value calculated more accurately using Equation 8 or Equation 10); and (ii) Equation 11 provides an acceptable approximation of $t_{\max }$ if the liquid thickness is less than one tenth of the height of the drainage layer (i.e. the difference in elevation between the top and the toe of the drainage layer slope). As a result, from a practical standpoint, Equation 11 is always valid in the case of geosynthetic drainage layers (and is then preferred to Equations 8 and 10 because it is simpler), and rarely valid in the case of granular drainage layers located on a slope that is not steep. Accordingly, in this paper, Equation 11 will be used systematically for geosynthetic drainage layers, such as geocomposites, and Equation 8 will be used systematically for granular drainage layers.

\subsection{Maximum head}

The equations presented in Sections 2.3 and 2.4 give the maximum liquid thickness of liquid in a single drainage layer. Equations that give the maximum head can be derived from equations that give the maximum liquid thickness. In the case of liquid flow parallel to a slope, the following relationship exists between liquid thickness, $t$, and head, $h$ :

$$
h \approx t \cos \beta
$$

As indicated by Giroud et al. (2000), Equation 13 is only approximate in the general case. However, Giroud et al. (2000) also indicated that Equation 13 provides a good approximation in the case of the maximum liquid thickness and the maximum head, which are the two important design parameters. Hence:

$$
h_{\max } \approx t_{\max } \cos \beta
$$

Equation 13 shows that the head is equal to the liquid thickness if the slope angle is small (e.g. $\cos \beta \approx 1.00$ for slopes less than $10 \%$ ) and is slightly smaller than the liquid thickness if the slope is steep (e.g. $\cos \beta=0.95$ for a $1 \mathrm{~V}: 3 \mathrm{H}$ slope).

Combining Equations 8 and 14 gives the following general equation for the head:

$$
h_{\max }=j \frac{\sqrt{\tan ^{2} \beta+4 q_{\mathrm{h}} / k}-\tan \beta}{2} L=j \frac{\sqrt{1+4 \lambda}-1}{2 / \tan \beta} L
$$


Combining Equations 11 and 14 gives the following equation for the head in the limit case defined in Section 2.4:

$$
h_{\max } \approx \frac{q_{\mathrm{h}} L}{k \tan \beta}=\lambda L \tan \beta
$$

\section{ANALYSIS}

\subsection{Introduction to the analysis}

\subsubsection{Flow configurations}

From the view point of flow configurations, two different slope sections should be considered: the upstream section and the downstream section (Figures 4 and 5). In the upstream section, all of the liquid supplied percolates vertically through the upper layer and is collected by the lower layer, where it flows along the slope. The length of the upstream section is such that the lower layer is full at the toe of the upstream section. In the downstream section, liquid flows both in the lower layer (which is full) and in the upper layer.

The liquid in the upper layer has different configurations in two cases depending on the value of the characteristic parameter for the upper layer, $\lambda_{2}$. This parameter is defined by the following equation, derived from Equation 7 with $k=k_{2}$ :

$$
\lambda_{2}=\frac{q_{\mathrm{h}}}{k_{2} \tan ^{2} \beta}
$$

In the first case, the liquid thickness is zero at the top of the downstream section of the upper layer (Figure 4). This occurs when $\lambda_{2}$ is equal to or less than 0.25 (Figures $3 b$ and $3 c)$.

In the second case, the liquid thickness is not zero at the top of the downstream section of the upper layer (Figure 5). This occurs when $\lambda_{2}$ is greater than 0.25 (Figure 3a). In this case, the flow can be described as follows:

- As indicated in Section 2.2, there is no flow through the vertical surface $\mathrm{VV}^{\prime}$ (Figures 3a and 5).

- As indicated in Section 2.2, a liquid profile must develop on the upstream side of $\mathrm{VV}^{\prime}$ as there is no flow
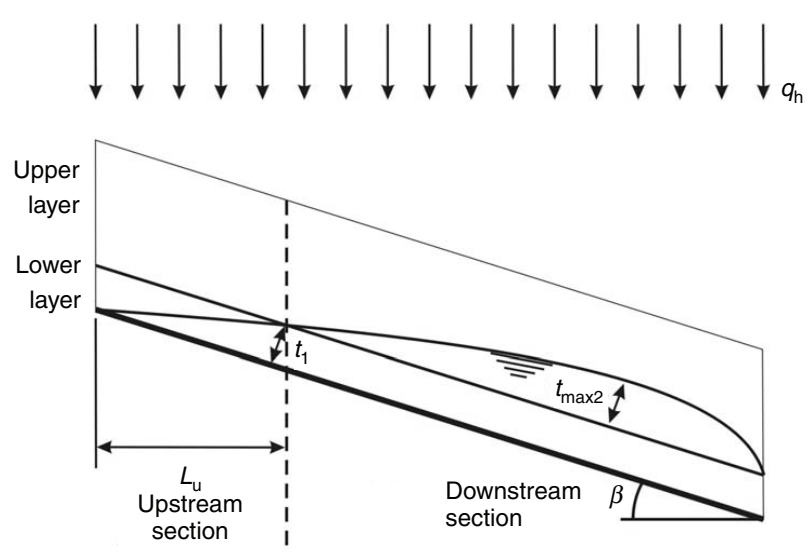

Figure 4. Flow configuration in the upstream section and the downstream section for the case where $\lambda_{2} \leq \mathbf{0 . 2 5}$
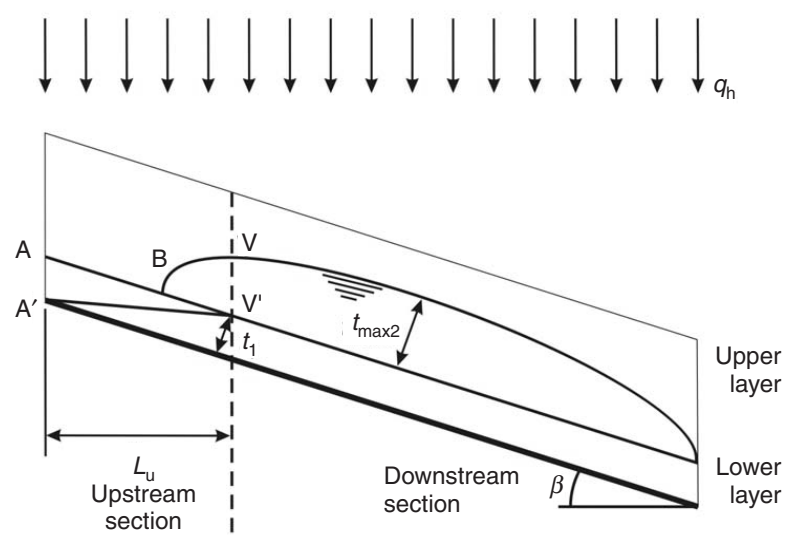

Figure 5. Flow configuration in the upstream section and the downstream section for the case where $\lambda_{2}>0.25$

through the vertical surface $\mathrm{VV}^{\prime}$. This leads to the formation of the saturated zone BVV' (Figure 5).

- When the steady state is reached (which is the case considered in this paper), the rate of liquid flow through BV (liquid surface) is equal to the rate of liquid flow through $\mathrm{BV}^{\prime}$ (dripping surface). Therefore the rate of liquid supply to the liquid surface $\mathrm{A}^{\prime} \mathrm{V}^{\prime}$ (i.e. to the upstream section of the lower layer) remains uniform, because it is not disturbed by the presence of the saturated zone BVV'.

- The triangular zone $\mathrm{AA}^{\prime} \mathrm{V}^{\prime}$ is unsaturated, which is possible because the hydraulic conductivity of the upper layer is smaller than the hydraulic conductivity of the lower layer.

Based on the foregoing discussion, even though the flow configurations in the upper layer are different in the two cases $\left(\lambda_{2} \leq 0.25\right.$ and $\left.\lambda_{2}>0.25\right)$, the rate of liquid supply to the lower layer is the same. Also, as indicated in Section 2.3, the same equation for calculating the liquid maximum thickness is applicable regardless of the value of $\lambda$ (i.e. the same equation can be used in the two cases). Therefore the two cases $\left(\lambda_{2} \leq 0.25\right.$ and $\left.\lambda_{2}>0.25\right)$ will be addressed together in the analysis presented hereafter.

\subsubsection{Overview of the analysis}

An analysis of flow in the lower layer will be presented first (Section 3.2). This analysis will give the value of the length of the upstream section, and will show that the lower layer conveys all of the liquid supplied to the upstream section and almost none of the liquid supplied to the downstream section.

An analysis of flow in the upper layer will then be presented (Section 3.3). The analysis will show that the upper layer conveys no flow in the upstream section. The analysis will also show that, in the downstream section, the upper layer conveys no liquid supplied to the upstream section and conveys virtually all of the liquid supplied to the downstream section.

\subsection{Flow in the lower layer}

\subsubsection{Flow in the upstream section of the lower layer}

As indicated in Section 3.1.1, the rate of liquid supply to the upstream section of the lower layer is uniform, 
regardless of the flow configuration in the upper layer. Therefore the rate of liquid supply is equal to $q_{\mathrm{h}}$ defined in Section 1.2.2.

As indicated in Section 1.2.1, the lower layer is assumed to be a geocomposite. Therefore the lower layer satisfies the conditions of validity of the limit case presented in Section 2.4. Consequently, in the upstream section of the lower layer, the liquid thickness varies linearly from zero at the top of the slope to $t_{1}$ at the point where the lower layer is full. Therefore the length of the upstream section, $L_{\mathrm{u}}$, can be calculated using the following equation, derived from Equation 12 with $x=L_{\mathrm{u}}, k=k_{1}$ and $t=t_{1}$ :

$$
L_{\mathrm{u}}=\frac{t_{1} k_{1} \sin \beta}{q_{\mathrm{h}}}
$$

Combining Equations 2 and 18 gives

$$
L_{\mathrm{u}}=\frac{\theta_{1} \sin \beta}{q_{\mathrm{h}}}
$$

It should be noted that, according to Section 2.4, the presence of a toe drain is not required to ensure the validity of Equations 18 and 19. The only requirement is that the downstream section be able to convey the flow rate that exists at the downstream end of the upstream section. This requirement is met, as indicated in Section 3.2.2.

If $L_{\mathrm{u}}$ calculated using Equation 18 or 19 is greater than $L$, the maximum liquid thickness is smaller than $t_{1}$ and all the liquid flow is conveyed by the geocomposite. In this case, the maximum liquid thickness is given by the following equation derived from Equation 11 with $k=k_{1}$ :

$$
t_{\max } \approx t_{\mathrm{lim}}=\frac{q_{\mathrm{h}}}{k_{1} \sin \beta} L
$$

and the maximum head is then given by the following equation, derived from Equation 16 with $k=k_{1}$ :

$$
h_{\max } \approx \frac{q_{\mathrm{h}} L}{k_{1} \tan \beta}
$$

If $L_{\mathrm{u}}$ is greater than $L$, the equations presented in the remainder of Section 3 are not needed and are not valid. The equations presented in the remainder of Section 3 are based on the assumption that $L_{\mathrm{u}}$ is smaller than $L$.

\subsubsection{Flow in the downstream section of the lower layer} The boundary conditions related to liquid flow in the downstream section of the lower layer are not simple, because liquid is supplied to the downstream section of the lower layer from the upstream section of the same layer and, possibly, from the downstream section of the upper layer. However, one feature of the flow in the lower layer is known: the downstream section of the lower layer is full of liquid over its entire length (as indicated in Section 3.1.1), except a very short length near the toe of the slope due to the presence of a perfect drain at the toe of the slope, as indicated at the end of Section 1.2.2.

The liquid present in the downstream section of the upper layer exerts a non-uniform pressure on the liquid flowing in the downstream section of the lower layer. As a result, the hydraulic gradient in the downstream section of the lower layer may be slightly reduced upstream of the location of $t_{\max 2}$ and slightly increased downstream of the location of $t_{\max 2}$. Consequently, there may be some small migration of liquid between the two layers in the downstream section (toward the upper layer upstream of the location of $t_{\max 2}$ and toward the lower layer downstream of the location of $t_{\max 2}$ ). These small migrations are neglected herein, which is equivalent to assuming that the boundary between the upper and lower layers in the downstream section is impermeable. In conclusion, the downstream section of the lower layer can be characterised as follows: (i) it can be assumed to be overlain by an impermeable boundary (as shown above); (ii) it is assumed to be underlain by an impermeable boundary (as indicated in Section 1.2.1); and (iii) it is full of liquid (as indicated in earlier in Section 3.2.2). Therefore the flow in the downstream section of the lower layer is confined.

Under confined, steady-state conditions, the hydraulic gradient in the downstream section of the lower layer, $i_{1 \text { down }}$, is constant over most of the length of the slope, and increases only near the toe of the slope owing to the presence of a perfect drain (Figure 6). The constant value of $i_{1 \text { down }}$ is given by the following classical equation:

$$
i_{\text {1down }}=\frac{\text { head loss }}{\text { slope length }}=\frac{\left(L-L_{\mathrm{u}}\right) \tan \beta}{\left(L-L_{\mathrm{u}}\right) / \cos \beta}=\sin \beta
$$

The rate of confined flow in the downstream section of the lower layer is then given by the following classical equation:

$$
\frac{Q_{1}}{B}=\theta_{1} i_{1 \text { down }}
$$

where $Q_{1} / B$ is the flow rate in the downstream section of the lower layer (in the direction parallel to the slope) per unit length in the horizontal direction perpendicular to the direction of the flow, and $Q_{1}$ is the flow rate in the downstream section of the lower layer (in the direction parallel to the slope).

Combining Equations 22 and 23 gives:

$$
\frac{Q_{1}}{B}=\theta_{1} \sin \beta
$$

The flow rate in the downstream section of the lower layer is then equal to the flow rate at the toe of the

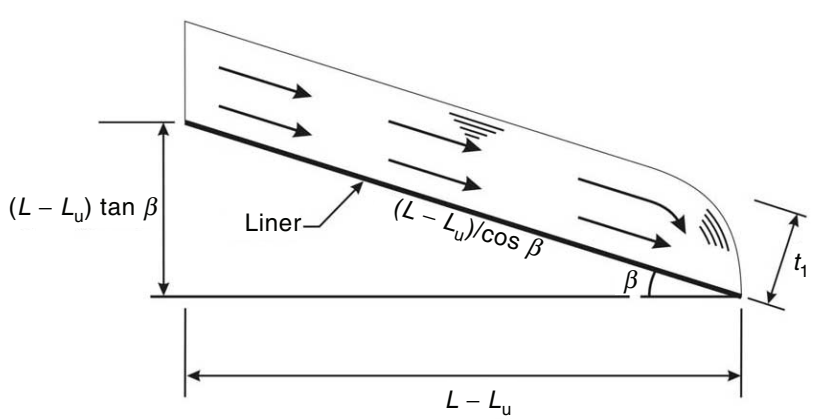

Figure 6. Confined flow in the downstream section of the lower layer 
upstream section of the lower layer. This is logical, under the assumptions presented above, because the only liquid entering the downstream section of the lower layer is the liquid flowing out of the toe of the upstream section of the lower layer.

\subsubsection{Conclusions for the lower layer}

The conclusion of the above discussion is that it can be assumed that the lower layer conveys all of the liquid supplied to the upstream section and none of the liquid supplied to the downstream section.

\subsection{Flow in the upper layer}

3.3.1. Flow in the upstream section of the upper layer As indicated in Section 3.1, the liquid that is supplied to the upstream section of the drainage system percolates through the upper layer and reaches the upstream section of the lower layer. This is true regardless of the considered case: the case for $\lambda_{2} \leq 0.25$ (Figure 4) and the case for $\lambda_{2}>0.25$ (Figure 5).

\subsubsection{Flow in the downstream section of the upper layer} (general case)

As indicated in Section 3.2.2, it may be conservatively assumed that the downstream section of the lower layer does not receive any liquid from the downstream section of the upper layer. Therefore the downstream section of the upper layer must convey all the liquid supplied to the downstream section, and equations presented in Section 2 for a drainage layer underlain by an impermeable liner can be used. As the upper layer is generally a granular layer, Equation 11 is generally not applicable and Equation 8 must be used. It is important to note that Equation 11 is valid regardless of the value of $\lambda$ : therefore it is applicable to both cases $\left(\lambda_{2} \leq 0.25\right.$ and $\left.\lambda_{2}>0.25\right)$.

The maximum thickness of liquid in the upper layer, $t_{\max 2}$, is given by the following equation derived from Equation 8 for the length of the downstream section (i.e. $\left.L-L_{\mathrm{u}}\right)$ :

$$
\begin{aligned}
t_{\max 2} & =j_{2} \frac{\sqrt{\tan ^{2} \beta+4 q_{\mathrm{h}} / k_{2}}-\tan \beta}{2 \cos \beta}\left(L-L_{\mathrm{u}}\right) \\
& =j_{2} \frac{\sqrt{1+4 \lambda_{2}}-1}{2} \frac{\tan \beta}{\cos \beta}\left(L-L_{\mathrm{u}}\right)
\end{aligned}
$$

where $\lambda_{2}$ is given by Equation 17 and $j_{2}$ is calculated using the following equation, derived from Equation 9 with $\lambda=\lambda_{2}$ :

$$
j_{2}=1-0.12 \exp \left\{-\left[\log \left(8 \lambda_{2} / 5\right)^{5 / 8}\right]^{2}\right\}
$$

Combining Equations 18 and 25 gives

$$
\begin{aligned}
t_{\max 2} & =j_{2} \frac{\sqrt{\tan ^{2} \beta+4 q_{\mathrm{h}} / k_{2}}-\tan \beta}{2 \cos \beta}\left(L-\frac{t_{1} k_{1} \sin \beta}{q_{\mathrm{h}}}\right) \\
& =j_{2} \frac{\sqrt{1+4 \lambda_{2}}-1}{2} \frac{\tan \beta}{\cos \beta}\left(L-\frac{t_{1} k_{1} \sin \beta}{q_{\mathrm{h}}}\right)
\end{aligned}
$$

Combining Equations 2 and 27 or 19 and 25 gives

$$
\begin{aligned}
t_{\max 2} & =j_{2} \frac{\sqrt{\tan ^{2} \beta+4 q_{\mathrm{h}} / k_{2}}-\tan \beta}{2 \cos \beta}\left(L-\frac{\theta_{1} \sin \beta}{q_{\mathrm{h}}}\right) \\
& =j_{2} \frac{\sqrt{1+4 \lambda_{2}}-1}{2} \frac{\tan \beta}{\cos \beta}\left(L-\frac{\theta_{1} \sin \beta}{q_{\mathrm{h}}}\right)
\end{aligned}
$$

3.3.3. Flow in the downstream section of the upper layer (limit case)

As indicated in Section 3.2.1, in all cases considered in this paper, the lower layer meets the conditions for the limit case equation described in Section 2.4. If the upper layer also meets the conditions for the limit case, the following equation derived from Equation 11 can be used for the upper layer:

$$
t_{\max 2}=\frac{q_{\mathrm{h}}\left(L-L_{\mathrm{u}}\right)}{k_{2} \sin \beta}
$$

Combining Equations 18 and 29 gives

$$
t_{\max 2}=\frac{q_{\mathrm{h}} L}{k_{2} \sin \beta}-\frac{t_{1} k_{1}}{k_{2}}
$$

Combining Equations 2 and 30 gives

$$
t_{\max 2}=\frac{q_{\mathrm{h}} L}{k_{2} \sin \beta}-\frac{\theta_{1}}{k_{2}}
$$

\subsection{Maximum liquid thickness}

\subsubsection{General equation}

The maximum liquid thickness occurs in the downstream section (Figures 4 and 5). It is equal to the thickness of the lower layer plus the maximum thickness of liquid in the upper layer:

$$
t_{\max }=t_{1}+t_{\max 2}
$$

3.4.2. Maximum liquid thickness in the general case Combining Equations 27 and 32 gives

$$
\begin{aligned}
t_{\max } & =t_{1}+j_{2} \frac{\sqrt{\tan ^{2} \beta+4 q_{\mathrm{h}} / k_{2}}-\tan \beta}{2 \cos \beta}\left(L-\frac{t_{1} k_{1} \sin \beta}{q_{\mathrm{h}}}\right) \\
& =t_{1}+j_{2} \frac{\sqrt{1+4 \lambda_{2}}-1}{2} \frac{\tan \beta}{\cos \beta}\left(L-\frac{t_{1} k_{1} \sin \beta}{q_{\mathrm{h}}}\right)
\end{aligned}
$$

Equation 33 is equivalent to the following equation, obtained by combining Equations 2 and 33 or 28 and 32:

$$
\begin{aligned}
t_{\max } & =t_{1}+j_{2} \frac{\sqrt{\tan ^{2} \beta+4 q_{\mathrm{h}} / k_{2}}-\tan \beta}{2 \cos \beta}\left(L-\frac{\theta_{1} \sin \beta}{q_{\mathrm{h}}}\right) \\
& =t_{1}+j_{2} \frac{\sqrt{1+4 \lambda_{2}}-1}{2} \frac{\tan \beta}{\cos \beta}\left(L-\frac{\theta_{1} \sin \beta}{q_{\mathrm{h}}}\right)
\end{aligned}
$$

In Equations 33 and 34, the dimensionless parameters $\lambda_{2}$ and $j_{2}$ are given by Equations 17 and 26 respectively. It should be remembered that $j_{2}$ varies between 0.88 and 1.00. Therefore using $j_{2}=1$ gives a conservative value of $t_{\max }$ (i.e. a value greater than the value that would be calculated rigorously).

\subsubsection{Maximum liquid thickness in the limit case}

The following equations are valid for the limit case where $\lambda_{2}$ is very small (e.g. $\lambda_{2}<0.01$ ). Combining 
Equations 30 and 32 gives the following approximate equation:

$$
t_{\max }=t_{1}+\frac{q_{\mathrm{h}} L}{k_{2} \sin \beta}-\frac{t_{1} k_{1}}{k_{2}}
$$

Hence:

$$
t_{\max }=\frac{q_{\mathrm{h}} L}{k_{2} \sin \beta}-\left(\frac{k_{1}}{k_{2}}-1\right) t_{1}
$$

Equations 35 and 36 are equivalent to the following equation, obtained by combining Equations 2 and 36 or 31 and 32:

$$
t_{\max }=\frac{q_{\mathrm{h}} L}{k_{2} \sin \beta}-\left(\frac{\theta_{1}}{k_{2}}-t_{1}\right)=\frac{q_{\mathrm{h}} L}{k_{2} \sin \beta}-\frac{\theta_{1}}{k_{2}}+t_{1}
$$

\subsection{Maximum head}

As indicated in Section 2.5, the maximum head is derived from the maximum liquid thickness using Equation 14.

\subsubsection{Maximum liquid head in the general case}

Combining Equations 14 and 33 gives the following equation for the maximum head in the general case:

$$
\begin{aligned}
h_{\max }= & t_{1} \cos \beta+j_{2} \frac{\sqrt{\tan ^{2} \beta+4 q_{\mathrm{h}} / k_{2}}-\tan \beta}{2} \\
& \times\left(L-\frac{t_{1} k_{1} \sin \beta}{q_{\mathrm{h}}}\right) \\
= & t_{1} \cos \beta+j_{2} \frac{\left(\sqrt{1+4 \lambda_{2}}-1\right) \tan \beta}{2} \\
& \times\left(L-\frac{t_{1} k_{1} \sin \beta}{q_{\mathrm{h}}}\right)
\end{aligned}
$$

Equation 38 is equivalent to the following equation, obtained by combining Equations 2 and 38 or 14 and 34:

$$
\begin{aligned}
h_{\max }= & t_{1} \cos \beta+j_{2} \frac{\sqrt{\tan ^{2} \beta+4 q_{\mathrm{h}} / k_{2}}-\tan \beta}{2} \\
& \times\left(L-\frac{\theta_{1} \sin \beta}{q_{\mathrm{h}}}\right) \\
= & t_{1} \cos \beta+j_{2} \frac{\left(\sqrt{1+4 \lambda_{2}}-1\right) \tan \beta}{2}\left(L-\frac{\theta_{1} \sin \beta}{q_{\mathrm{h}}}\right)
\end{aligned}
$$

In Equations 38 and 39, the dimensionless parameters $\lambda_{2}$ and $j_{2}$ are given by Equations 17 and 26 respectively. It should be remembered that $j_{2}$ varies between 0.88 and 1.00. Therefore using $j_{2}=1$ gives a conservative value of $h_{\max }$ (i.e. a value greater than the value that would be calculated rigorously).

\subsubsection{Maximum liquid head in the limit case}

Combining Equations 14 and 36 gives the following approximate equation for the limit case where $\lambda_{2}$ is very small (e.g. $\lambda_{2}<0.01$ ):

$$
h_{\max }=\frac{q_{\mathrm{h}} L}{k_{2} \tan \beta}-\left(\frac{k_{1}}{k_{2}}-1\right) t_{1} \cos \beta
$$

Equation 40 is equivalent to the following approximate equation, obtained by combining Equations 2 and 40 or 14 and 37 :

$$
\begin{aligned}
h_{\max } & =\frac{q_{\mathrm{h}} L}{k_{2} \tan \beta}-\left(\frac{\theta_{1}}{k_{2}}-t_{1}\right) \cos \beta \\
& =\frac{q_{\mathrm{h}} L}{k_{2} \tan \beta}-\frac{\theta_{1} \cos \beta}{k_{2}}+t_{1} \cos \beta
\end{aligned}
$$

\section{NUMERICAL APPLICATIONS}

\subsection{Method}

The method developed in Section 3 can be summarised as follows:

- Step 1. Calculate $L_{\mathrm{u}}$ using Equation 18 or 19 . If $L_{\mathrm{u}}$ is greater than or equal to $L$, the drainage geocomposite conveys all the liquid supplied. In this case, the maximum liquid thickness is smaller than the thickness of the geocomposite (i.e. $t_{\max }<t_{1}$ ). The maximum liquid thickness is then given by Equation 20 and the maximum head by Equation 21. If $L_{\mathrm{u}}$ is smaller than $L$, the drainage geocomposite conveys only a portion of the liquid supplied, and the maximum liquid thickness and the maximum head should be calculated as indicated in Step 2 below.

- Step 2 (only if $L_{\mathrm{u}}<L$ ). Calculate $\lambda_{2}$ using Equation 17. If $\lambda_{2}$ is smaller than 0.01 , the approximate equations for the limit case can be used (Equation 36 or 37 for the maximum liquid thickness, and Equation 40 or 41 for the maximum head). If $\lambda_{2}$ is greater than 0.01 , the equations for the general case must be used (Equation 33 or 34 for the maximum liquid thickness, and Equation 38 or 39 for the maximum head). The equations for the general case can also be used when the approximate equations for the limit case are valid.

Once the maximum liquid thickness and the maximum head are calculated, it should be checked that: (i) the maximum liquid thickness $\left(t_{\max }\right)$ is less than the total thickness of the drainage system $\left(t_{1}+t_{2}\right)$, or that the maximum liquid thickness in the upper layer $\left(t_{\max 2}\right)$ is less than the thickness of the upper layer $\left(t_{2}\right)$; and (ii) the maximum head is less than the prescribed value, if any. If these conditions are not met, the drainage system should be redesigned. Possible options include a drainage geocomposite with a greater hydraulic transmissivity, a sand with a greater hydraulic conductivity, a shorter drainage system, and a steeper slope.

\subsection{Design examples}

Three design examples are presented. The first example illustrates the general case (Sections 3.3.2 and 3.4.2), the second example illustrates the limit case (Sections 3.3.3 and 3.4.3), and the third example illustrates the case where the method presented in this paper is not needed (Section 3.2.1). 


\section{Example 1}

A leachate collection system consists of a drainage geocomposite overlain by a sand layer. The drainage geocomposite has a hydraulic transmissivity of $1.4 \times 10^{-5} \mathrm{~m}^{2} / \mathrm{s}$ and a thickness of $5 \mathrm{~mm}$. The sand layer has a hydraulic conductivity of $1 \times 10^{-5} \mathrm{~m} / \mathrm{s}$ and a thickness of $0.6 \mathrm{~m}$. The horizontal length of the leachate collection system is $15 \mathrm{~m}$ and its slope is $2 \%$. The rate of leachate supply considered in design is $25 \mathrm{~mm}$ in a week. Calculate the maximum head of leachate over the liner and compare it with the prescribed maximum leachate head, which is $0.3 \mathrm{~m}$.

First, the rate of liquid supply can be expressed in SI units as follows:

$$
q_{\mathrm{h}}=\frac{25 \times 10^{-3}}{(7)(86,400)}=4.134 \times 10^{-8} \mathrm{~m} / \mathrm{s}
$$

It should be noted that the rate of liquid supply is smaller than the hydraulic conductivity of the sand layer. Therefore the condition expressed by Equation 4 is satisfied, and the equations presented in this paper can be used.

Then, the length of the upstream section can be calculated using Equation 19 as follows:

$$
L_{\mathrm{u}}=\frac{\left(1.4 \times 10^{-5}\right) \sin \left(\tan ^{-1} 0.02\right)}{4.134 \times 10^{-8}}=6.772 \mathrm{~m}
$$

The calculated length of the upstream section is smaller than the length of the drainage layer. Therefore the drainage geocomposite cannot convey all the leachate supplied.

Next, $\lambda_{2}$ is calculated using Equation 17 as follows:

$$
\lambda_{2}=\frac{4.134 \times 10^{-8}}{\left(1 \times 10^{-5}\right)(0.02)^{2}}=10.335
$$

Then, $j_{2}$ is obtained from Table 1 or calculated using Equation 26 as follows:

$$
j_{2}=1-0.12 \exp \left\{-\left[\log (8 \times 10.335 / 5)^{5 / 8}\right]^{2}\right\}=0.9328
$$

Finally, the maximum head is calculated using Equation 39 as follows:

$$
\begin{aligned}
h_{\max }= & \left(5 \times 10^{-3}\right) \cos \left(\tan ^{-1} 0.02\right) \\
& +(0.9328) \frac{[\sqrt{1+(4)(10.335)}-1](0.02)}{2} \\
& \times\left[15-\frac{\left(1.4 \times 10^{-5}\right) \sin \left(\tan ^{-1} 0.02\right)}{4.134 \times 10^{-8}}\right] \\
= & 4.999 \times 10^{-3}+\left(5.137 \times 10^{-2}\right)(15-6.772) \\
= & 4.999 \times 10^{-3}+4.227 \times 10^{-1}=0.428 \mathrm{~m}
\end{aligned}
$$

The maximum head is greater than the prescribed value of $0.3 \mathrm{~m}$. Therefore the design should be changed. Possible options include a drainage geocomposite with a greater hydraulic transmissivity, a sand with a greater hydraulic conductivity, a shorter leachate collection system, and a steeper slope.
One could also have calculated the maximum liquid thickness using Equation 34 to compare it with the thickness of the drainage layer. Alternatively, the maximum liquid thickness can be derived from the above value of the maximum head using Equation 14 as follows:

$$
t_{\max }=\frac{0.428}{\cos \left(\tan ^{-1} 0.02\right)}=0.428 \mathrm{~m}
$$

The maximum liquid thickness thus calculated is smaller than the thickness of the drainage system, which is:

$$
t_{1}+t_{2}=0.005+0.6=0.605 \mathrm{~m}
$$

Of the two design criteria mentioned in Section 1.1, one is met (the liquid thickness is smaller than the thickness of the drainage system) and the other is not met (the maximum head is not smaller than the prescribed value). Therefore the considered drainage system is not acceptable.

\section{Example 2}

A drainage layer in a landfill cover system consists of a drainage geocomposite overlain by a sand layer. The drainage geocomposite has a hydraulic transmissivity of $1.4 \times 10^{-5} \mathrm{~m}^{2} / \mathrm{s}$ and a thickness of $5 \mathrm{~mm}$. The sand layer has a hydraulic conductivity of $3 \times 10^{-4} \mathrm{~m} / \mathrm{s}$ and a thickness of $0.3 \mathrm{~m}$. The horizontal length of the drainage layer is $30 \mathrm{~m}$ and its slope is $1 \mathrm{~V}: 4 \mathrm{H}$. The rate of liquid supply considered in design is $1.5 \times 10^{-7} \mathrm{~m} / \mathrm{s}$. Calculate the maximum head and compare it with the design criterion for the maximum head, which is $25 \mathrm{~mm}$.

It should be noted that the rate of liquid supply is smaller than the hydraulic conductivity of the sand layer. Therefore the condition expressed by Equation 4 is satisfied, and the equations presented in this paper can be used.

First, the length of the upstream section is calculated using Equation 19 as follows:

$$
L_{\mathrm{u}}=\frac{\left(1.4 \times 10^{-5}\right) \sin \left(\tan ^{-1} 0.25\right)}{1.5 \times 10^{-7}}=22.637 \mathrm{~m}
$$

The length of the upstream section is smaller than the length of the drainage layer, which indicates that the drainage geocomposite does not convey all the liquid supplied.

Then the value of $\lambda_{2}$ is calculated using Equation 17 as follows:

$$
\lambda_{2}=\frac{1.5 \times 10^{-7}}{\left(3 \times 10^{-4}\right)(0.25)^{2}}=8.00 \times 10^{-3}
$$

As $\lambda_{2}$ is smaller than 0.01 , the equation for the limit case, Equation 40, can be used. To use Equation 40, $k_{1}$ must be calculated using Equation 2 as follows:

$$
k_{1}=\frac{1.4 \times 10^{-5}}{5 \times 10^{-3}}=2.8 \times 10^{-3} \mathrm{~m} / \mathrm{s}
$$


Then, Equation 40 can be used as follows:

$$
\begin{aligned}
h_{\max }= & \frac{\left(1.5 \times 10^{-7}\right)(30)}{\left(3 \times 10^{-4}\right)(0.25)}-\left(\frac{2.8 \times 10^{-3}}{3 \times 10^{-4}}-1\right) \\
& \times\left(5 \times 10^{-3}\right) \cos \left(\tan ^{-1} 0.25\right) \\
= & 6.000 \times 10^{-2}-4.042 \times 10^{-2}=1.958 \times 10^{-2} \\
= & 0.0196 \mathrm{~m}=19.6 \mathrm{~mm}
\end{aligned}
$$

In fact, it is more convenient to use Equation 41, which does not require the calculation of $k_{1}$. Equation 41 is used as follows:

$$
\begin{aligned}
h_{\max }= & \frac{\left(1.5 \times 10^{-7}\right)(30)}{\left(3 \times 10^{-4}\right)(0.25)}-\left(\frac{1.4 \times 10^{-5}}{3 \times 10^{-4}}-5 \times 10^{-3}\right) \\
& \times \cos \left(\tan ^{-1} 0.25\right) \\
= & 6.000 \times 10^{-2}-4.042 \times 10^{-2}=1.958 \times 10^{-2} \\
= & 0.0196 \mathrm{~m}=19.6 \mathrm{~mm}
\end{aligned}
$$

The calculated maximum head is smaller than the design criterion for the maximum head. Therefore the considered drainage layer is acceptable from the viewpoint of the maximum head criterion.

Alternatively, the equation for the general case, Equation 39, can be used. To use Equation 39, $j_{2}$ must be obtained from Table 1 or calculated using Equation 26 as follows:

$$
j_{2}=1-0.12 \exp \left\{-\left[\log (8 \times 0.008 / 5)^{5 / 8}\right]^{2}\right\}=0.9704
$$

Then, the maximum head can be calculated using Equation 39 as follows:

$$
\begin{aligned}
h_{\max }= & \left(5 \times 10^{-3}\right) \cos \left(\tan ^{-1} 0.25\right) \\
& +(0.9704) \frac{\left[\sqrt{1+(4)\left(8.00 \times 10^{-3}\right)}-1\right](0.25)}{2} \\
& \times\left[30-\frac{\left(1.4 \times 10^{-5}\right) \sin \left(\tan ^{-1} 0.25\right)}{1.5 \times 10^{-7}}\right] \\
= & 4.851 \times 10^{-3}+\left(1.926 \times 10^{-3}\right)(30-22.637) \\
= & 4.851 \times 10^{-3}+1.418 \times 10^{-2}=0.0190 \mathrm{~m} \\
= & 19.0 \mathrm{~mm}
\end{aligned}
$$

It appears that using the approximate equation for the limit case, Equation 40 or 41, gave a very good approximation $(19.6 \mathrm{~mm})$ of the maximum head calculated more accurately $(19.0 \mathrm{~mm})$ using the equation for the general case, Equation 39.

One could also have calculated the maximum liquid thickness using Equation 34 or 37 to compare it with the thickness of the drainage layer. Alternatively, the maximum liquid thickness can be derived from the above value of the maximum head using Equation 14 as follows:

$$
t_{\max }=\frac{19.0}{\cos \left(\tan ^{-1} 0.25\right)}=19.6 \mathrm{~mm}
$$

The maximum liquid thickness thus calculated is smaller than the thickness of the drainage system, which is

$$
t_{1}+t_{2}=5+300=305 \mathrm{~mm}
$$

The two design criteria mentioned in Section 1.1 are met: the liquid thickness is smaller than the thickness of the drainage system, and the maximum head is smaller than the design criterion for the maximum head. Therefore the considered drainage system is acceptable. However, it is interesting to redo the calculations with a factor of safety of 2 on the rate of liquid supply to illustrate the sensitivity of the solution to a change in the liquid supply rate. With $q_{\mathrm{h}}=3 \times 10^{-7} \mathrm{~m} / \mathrm{s}$, the length of the upstream section, calculated using Equation 19, becomes

$$
L_{\mathrm{u}}=\frac{\left(1.4 \times 10^{5}\right) \sin \left(\tan ^{-1} 0.25\right)}{3 \times 10^{-7}}=11.318 \mathrm{~m}
$$

The length of the upstream section is smaller than the length of the drainage layer, which indicates that the drainage geocomposite does not convey all the liquid supplied.

Then, the value of $\lambda_{2}$ is calculated using Equation 17 as follows:

$$
\lambda_{2}=\frac{3 \times 10^{-7}}{\left(3 \times 10^{-4}\right)(0.25)^{2}}=0.016
$$

As $\lambda_{2}$ is greater than 0.01, Equation 39 must be used. To use Equation 39, $j_{2}$ must be obtained from Table 1 or calculated using Equation 26 as follows:

$$
j_{2}=1-0.12 \exp \left\{-\left[\log (8 \times 0.016 / 5)^{5 / 8}\right]^{2}\right\}=0.9554
$$

Then, the maximum head can be calculated using Equation 39 as follows:

$$
\begin{aligned}
h_{\max }= & \left(5 \times 10^{-3}\right) \cos \left(\tan ^{-1} 0.25\right) \\
& +(0.9554) \frac{[\sqrt{1+(4)(0.016)}-1](0.25)}{2} \\
& \times\left[30-\frac{\left(1.4 \times 10^{-5}\right) \sin \left(\tan ^{-1} 0.25\right)}{3 \times 10^{-7}}\right] \\
= & 4.851 \times 10^{-3}+\left(3.762 \times 10^{-3}\right)(30-11.318) \\
= & 4.851 \times 10^{-3}+7.028 \times 10^{-2} \\
= & 0.07513 \mathrm{~m}=75 \mathrm{~mm}
\end{aligned}
$$

Comparing this value of the maximum head with the value $(19 \mathrm{~mm})$ calculated in the case of a rate of liquid supply of $1.5 \times 10^{-7} \mathrm{~m} / \mathrm{s}$ shows that, in this particular case, the head is multiplied by 4 when the liquid supply rate is multiplied by 2 . Therefore design engineers must select the value of the liquid supply rate very carefully.

\section{Example 3}

This example is the same as Example 1, except that the geocomposite has a hydraulic transmissivity of $5 \times 10^{-5} \mathrm{~m}^{2} / \mathrm{s}$. 
The length of the upstream section can be calculated using Equation 19 as follows:

$$
L_{\mathrm{u}}=\frac{\left(5 \times 10^{-5}\right) \sin \left(\tan ^{-1} 0.02\right)}{4.134 \times 10^{-8}}=24.185 \mathrm{~m}
$$

The calculated length of the upstream section is greater than the length of the drainage layer. Therefore the drainage geocomposite can convey all the leachate supplied.

In this case, the maximum head is given by Equation 21. To use Equation 21, it is necessary to first calculate the hydraulic conductivity of the geocomposite using Equation 2 as follows:

$$
k_{1}=\frac{5 \times 10^{-5}}{5 \times 10^{-3}}=1.0 \times 10^{-2} \mathrm{~m} / \mathrm{s}
$$

Then, the maximum head is calculated using Equation 21 as follows:

$$
h_{\max } \approx \frac{\left(4.134 \times 10^{-8}\right)(15)}{\left(1 \times 10^{-2}\right)(0.02)}=3.10 \times 10^{-3} \mathrm{~m}=3.1 \mathrm{~mm}
$$

The maximum liquid thickness can be calculated using Equation 20. Alternatively, it can be derived from the value of the maximum head calculated above using Equation 14 as follows:

$$
t_{\max }=\frac{3.1}{\cos \left(\tan ^{-1} 0.02\right)}=3.1 \mathrm{~mm}
$$

It should be noted that, as $L_{\mathrm{u}}$ is greater than the length of the drainage layer, it was obvious that $t_{\max }$ would be less than the thickness of the geocomposite $(5 \mathrm{~mm})$.

\section{DISCUSSION}

\subsection{Use of basic cases to check the equations}

Two basic cases are used to check the validity of the equations proposed in Section 3: the case where the two layers consist of identical geocomposites, and the case where $L_{\mathrm{u}}=L$.

\subsubsection{Case of two identical geocomposites}

If the upper layer consists of a geocomposite identical to the lower layer geocomposite, Equation 36 can be used with $k_{1}=k_{2}=k$, which gives

$$
t_{\max }=\frac{q_{\mathrm{h}}}{k \sin \beta} L
$$

Equation 42 is identical to Equation 11, which confirms the validity of Equation 36.

5.1.2. Case where $L_{\mathrm{u}}=L$

If $L_{\mathrm{u}}=L$, the lower layer geocomposite is just sufficient to convey all of the liquid supplied to the drainage layer. Therefore $t_{\max }=t_{1}$. Indeed, Equation 25 with $L_{\mathrm{u}}=L$ gives $t_{\max 2}=0$, and Equation 32 with $t_{\max 2}=0$ gives $t_{\max }=t_{1}$, which confirms Equation 25. The same result would be obtained by combining Equations 18 and 20 with $L_{\mathrm{u}}=L$, which further confirms Equation 25 .

\subsection{Evaluation of the average hydraulic conductivity approach}

In the past, an approach different from that used in this paper has been used to address flow in a drainage system composed of two layers. This approach consists in calculating an average hydraulic conductivity for the two-layer system.

This type of approach is used, for example, in the HELP model. The HELP model is a computer program based on a water balance method that accounts for precipitation, runoff and evapotranspiration to determine the rate of infiltration of precipitation water into a landfill, the rate of percolation of water through the cover soil, the rate of leachate generation, and the impingement rate of leachate onto the leachate collection layer. Then the HELP model calculates the head of leachate in the leachate collection layer using McEnroe's equations (McEnroe 1993). As shown by Giroud et al. (2000), Equation 15 and McEnroe's equations give almost exactly the same values for the maximum head, but Equation 15 is much simpler and less prone to mathematical errors. In the case of a drainage system composed of two layers, the HELP model replaces the two layers by a single layer having an average hydraulic conductivity calculated using the average head. For the sake of simplicity, this approach is described below using the maximum liquid thickness.

The average hydraulic conductivity of the two-layer system can be defined as follows:

$$
k_{\mathrm{avg}}=\frac{k_{1} t_{1}+k_{2}\left(t_{\max }-t_{1}\right)}{t_{\max }}
$$

As Equation 43 includes $t_{\max }$, which is unknown, iterations are necessary to calculate $k_{\text {avg }}$ and $t_{\max }$. These iterations are tedious. Furthermore, they are useless because an explicit solution for $t_{\max }$ can be obtained by eliminating $k_{\text {avg }}$ between Equation 43 and the following equation derived from Equation 8:

$$
t_{\max }=j \frac{\sqrt{\tan ^{2} \beta+4 q_{\mathrm{h}} / k_{\mathrm{avg}}}-\tan \beta}{2 \cos \beta} L
$$

This elimination of $k_{\mathrm{avg}}$ between Equation 43 and Equation 44 would require lengthy (but simple) calculations involving a quadratic equation. The value of $t_{\max }$ that would be thus obtained would be different from Equation 33, which is the solution developed in this paper.

In the limit case, the following equation derived from Equation 11 would be used instead of Equation 44:

$$
t_{\max }=\frac{q_{\mathrm{h}}}{k_{\mathrm{avg}} \sin \beta} L
$$

Eliminating $k_{\text {avg }}$ between Equations 43 and 45 gives an equation identical to Equation 35, which is the solution developed in this paper for the limit case. Clearly, the average hydraulic conductivity approach happens to give a correct result only in the limit case and is not valid for the general case, which is the relevant case for the typical situation of a geocomposite overlain by sand (Figure 1). 
From a physical standpoint, it should be noted that, while the approach proposed in this paper corresponds to plausible flow configurations (Figures 4 and 5), the average hydraulic conductivity approach does not correspond to any identified flow configuration.

In conclusion, for all of the above reasons, the hydraulic conductivity average approach (i.e. the approach used in the HELP model) cannot be recommended.

\subsection{Evaluation of the liquid supply fraction approach}

While the senior author was developing the equations presented in Section 3, a different approach was suggested. This approach is not consistent with the flow configurations shown in Figures 4 and 5. However, as this approach was considered at some point, it is appropriate to discuss it in this paper. This approach consists of assuming that the geocomposite (i.e. the lower layer) conveys the fraction of the liquid supply that it can convey, and the upper layer conveys the rest. This approach is called herein the 'liquid supply fraction approach'. The principle of the liquid supply fraction approach is similar to the principle of the approach used in this paper. However, the implementation is different:

- In this paper, the lower layer conveys all the liquid supplied to the upstream section, whereas the upper layer conveys all the liquid supplied to the downstream section. The upper layer conveys no flow in the upstream section, whereas the lower layer conveys in the downstream section only the liquid collected in the upstream section.

- With the liquid supply fraction approach, both layers somehow convey two complementary fractions of the liquid from the top to the bottom of the slope.

Numerical examples and an analysis presented in Appendix A show that the liquid supply fraction approach overestimates the maximum liquid thickness and maximum head, in particular when the characteristic parameter $\lambda$ is large.

From a physical standpoint, it should be noted that, whereas the solution proposed in this paper corresponds to plausible flow configurations (Figures 4 and 5), the liquid supply fraction approach does not correspond to any identified flow configuration. In fact, it is unclear how the liquid supply could be split between the two layers from the top of the slope.

In conclusion, for all of the above reasons, the liquid supply fraction approach cannot be recommended.

\subsection{Equation proposed in the literature}

The authors of this paper found in the literature one publication (Masada 1998) that addresses the case of drainage systems composed of two layers including a geosynthetic drainage material. In that publication, it is indicated that the maximum depth of liquid can be derived from two equations numbered 25 and 26 in that publication, but referred to herein as M-25 and M-26 to avoid confusion with equations presented herein. In the publication by Masada, it is indicated that 'no attempt is made to combine Equations M-25 and M-26 to arrive at an explicit expression for the maximum depth because the form of Equation M-26 is complicated'. Therefore, in the publication by Masada (1998), no explicit solution is proposed for the maximum liquid depth, thickness or head in the case of drainage systems composed of two layers including a geosynthetic drainage material. Furthermore, Equation M-25 by Masada (1998) is an extension of equations developed by the same author for drainage systems that consist of a single layer. Giroud et al. (2000, p. 377) have shown that these equations give results that can be 'very inaccurate'. Therefore it may be concluded that no adequate solution has been proposed by Masada for drainage systems composed of two layers including a geosynthetic drainage material.

\subsection{Slope stability considerations}

Liquid flowing parallel to a slope generates seepage forces that are detrimental to the stability of the drainage layer and the associated layers of soils and geosynthetics. The seepage forces are independent of flow velocity and independent of the hydraulic conductivity of the medium in which liquid is flowing; the impact of flowing liquid on stability is proportional to the thickness of liquid (Giroud et al. 1995). As illustrated by the examples presented in Section 4.2, the liquid thickness in sand is much greater than in the geocomposite. Therefore allowing liquid to flow parallel to the slope in a sand layer overlying a geocomposite significantly impairs the stability of the slope. Even though a method is presented herein to design drainage systems composed of two layers, this paper should not be construed as an encouragement to allow liquid to flow in sand layers overlying geosynthetics. On the contrary, the authors recommend the use of geocomposites with a high hydraulic transmissivity in order to convey all the collected liquid within the geocomposite. When all of the liquid flows in the geocomposite, the impact of flow on stability is negligible because the liquid thickness is then very small. Another benefit is that the rate of leakage through the liner underlying the geocomposite is very small because the head is small.

When stability is a concern, precautions must be taken. One of them consists in using a textured geomembrane and a geocomposite including two geotextiles heat-bonded to the geosynthetic drainage medium. The upper geotextile functions as a filter, whereas the lower geotextile functions as a friction layer that ensures high interface shear strength between the geocomposite and the textured geomembrane. (See the first paragraph of Section 1.1.)

\subsection{Limitations}

The method of analysis presented in this paper has the following limitations: (i) the hydraulic conductivity of the upper layer of the drainage system must be smaller than that of the lower layer; and (ii) the lower layer must be such that the equations for the limit case (defined in Section 2.4) must be applicable to the lower layer. To that end, the characteristic parameter $\lambda_{1}$ must be small 
(e.g. $\lambda_{1}<0.01$ ), with $\lambda_{1}$ given by the following equation derived from Equation 7 with $k=k_{1}$ :

$$
\lambda_{1}=\frac{q_{\mathrm{h}}}{k_{1} \tan ^{2} \beta}
$$

This is always the case with currently available geocomposites, and it is generally the case with gravel. In contrast, it is not the case with sand, unless the slope is steep. This theoretical limitation does not significantly limit the use of the method because the lower layer is generally a geocomposite (i.e. a material for which $\lambda_{1}$ is always small). However, it is clear that the method presented in this paper is not applicable to the case of two sand layers on top of each other.

\section{CONCLUSIONS}

This paper provides a rational approach to the design of drainage layers composed of two layers: a geocomposite overlain by another material, typically sand. The equations presented in this paper are simple and can be used by hand. They provide the maximum liquid thickness and the maximum head as a function of the rate of liquid supply, the hydraulic conductivities of the two layers, the length of the drainage system, and the slope. Design examples are also provided. The proposed method was compared with other methods, and it was shown that the other methods provide incorrect results except in the limit case.

It is important to note that, even though this paper provides a method for designing drainage systems composed of two layers, the authors of this paper do not encourage the use of drainage systems where a significant amount of liquid flows in a sand layer overlying a geocomposite.

\section{ACKNOWLEDGEMENTS}

The support of GeoSyntec Consultants is acknowledged. The authors acknowledge the anonymous peer review system of Geosynthetics International, which led to significant improvements of the paper.

\section{NOTATIONS}

Basic SI units are given in parentheses.

$B$ unit length in horizontal direction perpendicular to direction of flow $(\mathrm{m})$

$h$ head above liner $(\mathrm{m})$

$h_{\max }$ maximum head above liner, simply called 'head' (m)

$i_{1 \text { down }}$ hydraulic gradient in downstream section of lower layer (dimensionless)

$j$ parameter, called 'modifying factor', defined by Equation 9 (dimensionless)

$j_{2} \quad$ value of $j$ for $\lambda=\lambda_{2}$ (dimensionless)

$k$ hydraulic conductivity of drainage material in direction of flow $(\mathrm{m} / \mathrm{s})$

$k_{\text {avg }}$ average hydraulic conductivity of two layers used in HELP model approach $(\mathrm{m} / \mathrm{s})$ $k_{1} \quad$ hydraulic conductivity of drainage material used in lower layer $(\mathrm{m} / \mathrm{s})$

$k_{2} \quad$ hydraulic conductivity of drainage material used in upper layer $(\mathrm{m} / \mathrm{s})$

$L$ horizontal projection of length of drainage layer in direction of flow $(\mathrm{m})$

$L_{\mathrm{u}} \quad$ length of upstream section of drainage layer (m)

$Q$ flow rate in a drainage system (in direction parallel to slope) $\left(\mathrm{m}^{3} / \mathrm{s}\right)$

$Q / B$ flow rate in a drainage system (in direction parallel to slope) per unit length in horizontal direction perpendicular to direction of flow $\left(\mathrm{m}^{2} / \mathrm{s}\right)$

$Q_{1} \quad$ flow rate in downstream section of lower layer (in direction parallel to slope) $\left(\mathrm{m}^{3} / \mathrm{s}\right)$

$Q_{1} / B$ flow rate in downstream section of lower layer (in direction parallel to slope) per unit length in horizontal direction perpendicular to direction of flow $\left(\mathrm{m}^{2} / \mathrm{s}\right)$

$q_{\mathrm{h}}$ liquid impingement rate (i.e. rate of liquid supply per unit horizontal area) $(\mathrm{m} / \mathrm{s})$

$t$ liquid thickness (m)

$t_{1}$ thickness of lower layer (m)

$t_{2}$ thickness of upper layer (m)

$t_{\mathrm{lim}}$ maximum liquid thickness in limit case where $q_{\mathrm{h}}$ is small and $\beta$ and $k$ are large (i.e. case where $\lambda$ is very small, e.g. $\lambda<0.01)(\mathrm{m})$

$t_{\max }$ maximum liquid thickness (m)

$t_{\max 2}$ maximum liquid thickness in upper layer $(\mathrm{m})$

$x$ distance measured horizontally from top of slope $(\mathrm{m})$

$\beta$ slope angle of drainage system $\left(^{\circ}\right)$

$\theta_{1}$ hydraulic transmissivity of lower layer $\left(\mathrm{m}^{2} / \mathrm{s}\right)$

$\theta_{2}$ hydraulic transmissivity of upper layer $\left(\mathrm{m}^{2} / \mathrm{s}\right)$

$\lambda$ parameter defined by Equation 7 (dimensionless)

$\lambda_{2}$ value of $\lambda$ for $k=k_{2}$ (dimensionless)

\section{REFERENCES}

Giroud, J. P. \& Houlihan, M. F. (1995). Design of leachate collection layers. Proceedings of the 5th International Landfill Symposium, Sardinia, Vol. 2, pp. 613-640.

Giroud, J. P., Bachus, R. C. \& Bonaparte, R. (1995). Influence of water flow on the stability of geosynthetic-soil layered systems on slopes. Geosynthetics International, 2, No. 6, 1149-1180.

Giroud, J. P., Zornberg, J. G. \& Zhao, A. (2000). Hydraulic design of geosynthetic and granular liquid collection layers. Geosynthetics International, 7, Nos. 4-6, 285-380.

Masada, T. (1998). Leachate flow mound equations for steady-state flow over a landfill geosynthetic bottom liner. Geosynthetics International, 5, No. 4, 383-397.

McEnroe, B. M. (1993). Maximum saturated depth over landfill liner. Journal of Environmental Engineering, ASCE, 119, No. 2, 262-270.

\section{APPENDIX A. EVALUATION OF THE LIQUID SUPPLY FRACTION APPROACH}

The liquid supply fraction approach evaluated in Appendix A consists of assuming that the geocomposite (i.e. the lower layer) conveys the fraction of the liquid supply that it can convey, and the upper layer conveys the rest. This approach is illustrated by two examples: Example 4 is identical to Example 1, and Example 5 is identical to Example 2. (Examples 1 and 2 are presented 
in the main text of this paper.) Whereas Examples 1 and 2 are solved with the recommended method, Examples 4 and 5 are addressed with the liquid supply fraction approach.

\section{Example 4}

Considering the conditions given for Example 1, the maximum flow rate per unit width that the lower layer (i.e. the geocomposite) can convey is given as follows by Equation 24:

$$
\begin{aligned}
Q_{1} / B & =\theta_{1} \sin \beta=\left(1.4 \times 10^{-5}\right) \sin \left(\tan ^{-1} 0.02\right) \\
& =2.7994 \times 10^{-7} \mathrm{~m}^{2} / \mathrm{s}
\end{aligned}
$$

This flow rate per unit width corresponds to a liquid supply rate of

$$
\begin{aligned}
q_{\mathrm{h} 1} & =\frac{2.7994 \times 10^{-7}}{L}=\frac{2.7994 \times 10^{-7}}{15} \\
& =1.8663 \times 10^{-8} \mathrm{~m} / \mathrm{s}
\end{aligned}
$$

This is less than the rate of liquid supply, which is $4.134 \times 10^{-8} \mathrm{~m} / \mathrm{s}$ according to Example 1. Therefore it is assumed that the remainder of the liquid supply is conveyed by the upper layer (i.e. the sand). The remainder of the liquid supply is

$$
q_{\mathrm{h} 2}=4.134 \times 10^{-8}-1.866 \times 10^{-8}=2.268 \times 10^{-8} \mathrm{~m} / \mathrm{s}
$$

Then, $\lambda_{2}$ is calculated using Equation 17 as follows:

$$
\lambda_{2}=\frac{2.268 \times 10^{-8}}{\left(1 \times 10^{-5}\right)(0.02)^{2}}=5.669
$$

Then, $j_{2}$ is obtained from Table 1 or calculated using Equation 26 as follows:

$$
j_{2}=1-0.12 \exp \left\{-\left[\log (8 \times 5.669 / 5)^{5 / 8}\right]^{2}\right\}=0.9161
$$

Then, $t_{\max 2}$ is calculated using Equation 8 as follows:

$$
\begin{aligned}
t_{\max 2}= & (0.9161) \frac{\sqrt{1+(4)(5.669)}-1}{2} \\
& \times\left[\frac{0.02}{\cos \left(\tan ^{-1} 0.02\right)}\right](15)=0.531 \mathrm{~m}
\end{aligned}
$$

This calculated value of $t_{\max 2}$ is to be added to the thickness of the geocomposite. Hence:

$$
t_{\max }=0.005+0.531=0.536 \mathrm{~m}
$$

The maximum head is derived from the maximum liquid thickness using Equation 14 as follows:

$$
h_{\max }=0.536 \times \cos \left(\tan ^{-1} 0.02\right)=0.536 \mathrm{~m}
$$

This value is significantly greater than the value obtained in Example $1(0.428 \mathrm{~m})$. The error resulting from the liquid supply fraction approach is $25 \%$.

\section{Example 5}

Considering the conditions given for Example 2, the maximum flow rate per unit width that the lower layer (i.e. the geocomposite) can convey is given as follows by Equation 24:

$$
\begin{aligned}
Q_{1} / B & =\theta_{1} \sin \beta=\left(1.4 \times 10^{-5}\right) \sin \left(\tan ^{-1} 0.25\right) \\
& =3.3955 \times 10^{-6} \mathrm{~m}^{2} / \mathrm{s}
\end{aligned}
$$

This flow rate per unit width corresponds to a liquid supply rate of

$$
\begin{aligned}
q_{\mathrm{h} 1} & =\frac{3.3955 \times 10^{-6}}{L}=\frac{3.3955 \times 10^{-6}}{30} \\
& =1.1318 \times 10^{-7} \mathrm{~m} / \mathrm{s}
\end{aligned}
$$

This is less than the rate of liquid supply, which is $1.5 \times 10^{-7} \mathrm{~m} / \mathrm{s}$. Therefore it is assumed that the remainder of the liquid supply is conveyed by the upper layer (i.e. the sand). The remainder of the liquid supply is

$$
q_{\mathrm{h} 2}=1.5 \times 10^{-7}-1.1318 \times 10^{-7}=3.682 \times 10^{-8} \mathrm{~m} / \mathrm{s}
$$

Then, $\lambda_{2}$ is calculated using Equation 17 as follows:

$$
\lambda_{2}=\frac{3.682 \times 10^{-8}}{\left(3 \times 10^{-4}\right)(0.25)^{2}}=1.964 \times 10^{-3}
$$

This value of $\lambda_{2}$ is very small: therefore the equation for the limit case, Equation 11, can be used. Hence:

$$
\begin{aligned}
t_{\max 2} & =\frac{q_{\mathrm{h} 2} L}{k_{2} \sin \beta}=\frac{\left(3.682 \times 10^{-8}\right)(30)}{\left(3 \times 10^{-4}\right) \sin \left(\tan ^{-1} 0.25\right)} \\
& =0.0152 \mathrm{~m}
\end{aligned}
$$

This calculated value of $t_{\max 2}$ is to be added to the thickness of the geocomposite. Hence:

$$
t_{\max }=0.005+0.0152=0.0202 \mathrm{~m}
$$

The maximum head is then derived from the maximum liquid thickness using Equation 14 as follows:

$$
\begin{aligned}
h_{\max } & =0.0202 \times \cos \left(\tan ^{-1} 0.25\right)=0.0196 \mathrm{~m} \\
& =19.6 \mathrm{~mm}
\end{aligned}
$$

Table 2. Values of the ratio between $t_{\max } / k$ and $q_{\mathrm{h}} / L$ (with values of $\lambda$ in parentheses)

\begin{tabular}{|c|c|c|c|}
\hline \multirow{2}{*}{$q_{\mathrm{h}} / k$} & \multicolumn{3}{|c|}{$\tan \beta$} \\
\cline { 2 - 4 } & 0.02 & $1 / 3$ & 1.0 \\
\hline $1 \times 10^{-9}$ & $50.0\left(\lambda=2.5 \times 10^{-6}\right)$ & $3.16\left(\lambda=9 \times 10^{-9}\right)$ & $1.41\left(\lambda=1 \times 10^{-9}\right)$ \\
$1 \times 10^{-8}$ & $50.0\left(\lambda=2.5 \times 10^{-5}\right)$ & $3.16\left(\lambda=9 \times 10^{-8}\right)$ & $1.41\left(\lambda=1 \times 10^{-8}\right)$ \\
$1 \times 10^{-7}$ & $49.9\left(\lambda=2.5 \times 10^{-4}\right)$ & $3.16\left(\lambda=9 \times 10^{-7}\right)$ & $1.41\left(\lambda=1 \times 10^{-7}\right)$ \\
$1 \times 10^{-5}$ & $46.1\left(\lambda=2.5 \times 10^{-2}\right)$ & $3.16\left(\lambda=9 \times 10^{-5}\right)$ & $1.41\left(\lambda=1 \times 10^{-5}\right)$ \\
$1 \times 10^{-3}$ & $20.8(\lambda=2.5)$ & $3.03\left(\lambda=9 \times 10^{-3}\right)$ & $1.40\left(\lambda=1 \times 10^{-3}\right)$ \\
$1 \times 10^{-1}$ & $3.0(\lambda=250)$ & $1.77\left(\lambda=9 \times 10^{-1}\right)$ & $1.17\left(\lambda=1 \times 10^{-1}\right)$ \\
\hline
\end{tabular}


This value is the same as the approximate value obtained in Example 2 using the limit case equation.

From the above examples, it appears that the liquid supply fraction approach overestimates the maximum head in the general case, but gives a good approximation of the maximum head in the limit case. This is confirmed by the following analysis.

With the liquid supply fraction approach discussed above, $t_{\max 2}$ is calculated with an underestimated value of the liquid supply (i.e. $q_{\mathrm{h} 2}$ instead of $q_{\mathrm{h}}$ ) and an overestimated value of the flow path (i.e. $L$ instead of $L-L_{\mathrm{u}}$ ). To evaluate the liquid supply fraction ap- proach, the sensitivity of $t_{\max 2}$ to $q_{\mathrm{h}} / L$ should be evaluated. To that end, Table 2, derived from table 2 of the paper by Giroud et al. (2000, p. 305) was developed. Table 2 shows that, for small values of $\lambda$ (i.e. when the limit case equations are valid), the ratio $\left(t_{\max } / k\right) /\left(q_{\mathrm{h}} / L\right)$ is constant (i.e. $t_{\max }$ is not sensitive to $q_{\mathrm{h}} / L$ ), whereas, for large values of $\lambda$ (i.e. when the limit case equations are not valid), decreasing $q_{\mathrm{h}}$ (i.e. using underestimated values of $q_{\mathrm{h}}$ ) leads to an increase of $t_{\max } /\left(q_{\mathrm{h}} / L\right)$. This is consistent with the results of the above examples and shows that the conclusions drawn from the above examples can be generalized.

The Editors welcome discussion in all papers published in Geosynthetics International. Please email your contribution to discussion@geosynthetics-international.com by 15 September 2004 